\title{
Calculation of Technical Efficiency of Chinese Renewable Resources Industry and Empirical Study on Its Influence Factors: DEA-Tobit Analysis
}

\author{
Shiqi Cao \\ School of Economics, Shanghai University, Shanghai, China
}

Email address:

csqi2173@163.com

To cite this article:

Shiqi Cao. Calculation of Technical Efficiency of Chinese Renewable Resources Industry and Empirical Study on Its Influence Factors: DEA-Tobit Analysis. Science Innovation. Vol. 6, No. 1, 2018, pp. 46-53. doi: 10.11648/j.si.20180601.19

Received: February 11, 2018; Accepted: April 2, 2018; Published: May 23, 2018

\begin{abstract}
This paper collates the respected study of renewable resources industry and measures,applying DEA,the technical efficiency of the renewable resource industry in 17 provinces and cities of China in the past 2010-2015 years.Furthermore, the Tobit regression model is applied to analyze the external factors that influence the pure technical efficiency and the scale efficiency of renewable resources industry.The results show that for pure technical efficiency, renewable resources industry of provinces in Middle East region has the advantage, while,the Midwest provinces' performed better than the eastern provinces' in scale efficiency; Pure technical efficiency is positively related to the development of the industry and the service sector,in the contrast,there is no positive impact on it concerning about factors of the development of regional economy, the level of opening up, the level of technological innovation and the level of education;Scale efficiency is positively affected by the regional economic development, the level of opening up,the level of technological innovation, while the level of education, the level of industrial development and the development of the service sector has negative impact on it.
\end{abstract}

Keywords: Renewable Resources Industry, Technical Efficiency, DEA, Influence Factors

\section{中国再生资源产业技术效率评价及其影响因素分析一 基于DEA-Tobit两步法}

\section{曹诗琪}

经济学院, 上海大学, 上海, 中国

\section{邮箱}

csqi2173@163.com

\begin{abstract}
摘要: 本文梳理了再生资源产业的相关研究, 通过DEA方法测度了2010-2015年中国17个省市再生资源产业的技术效率 水平, 并运用Tobit回归模型对再生资源产业纯技术效率和规模效率的外部影响因素进行了分析。结果表明，在纯技术 效率方面, 中东部地区省市再生资源产业占有优势, 而在规模效率方面, 中西部地区省市表现好于东部地区省市; 纯 技术效率受到工业和第三产业发展的正向影响，区域经济发展水平，对外开放水平，技术创新水平以及教育水平没有 对其产生积极影响; 规模效率受区域经济发展水平、对外开放程度和技术创新水平的正向影响, 而教育水平、工业发 展水平和第三产业发展水平对其影响是负向的。
\end{abstract}


关键词: 再生资源产业, 技术效率, DEA, 影响因素

\section{1. 引言}

自上世纪 80 年代以来, 人口剧增, 资源短缺、环境污 染、生态破坏等问题成为影响世界各国经济社会发展的重 要因素, 可持续发展、循环经济等概念在这一背景下相继 被提出。在寻求经济社会可持续发展的实践过程中, 人们 发现, 再生资源中蕴含巨大的经济、社会和生态价值, 因 此, 与再生资源相关的产业开始受到发达国家的重视与扶 持。目前, 西欧、美国和日本等发达国家的再生资源回收 利用率已达到 $90 \%$ 左右, 回收加工水平较高。

在中国，再生资源产业起步较晚。2005年政府开始将 工业废弃物综合利用、再生资源回收利用产业化作为产业 结构调整的指导任务, 开始了再生资源的产业化。2008 年推出《循环经济促进法》, 规范再生资源产业发展, 并 在后续实施了一系列政策规划, 不断推动再生资源产业在 中国的发展。

然而, 中国再生资源产业经过2010年到2013年快速发 展后, 受到经济下行因素以及自身存在的多种问题影响, 进入瓶颈期，2015年中国再生资源产业规模以上企业有 1526 家，同比增长 $13 \%$, 同年, 包含废旧金属, 废弃电气 电子产品、报废汽车、废玻璃、废纸、废电池等在内十大 类别的再生资源回收总量约为 2.46 亿吨, 同比增长仅有 $0.3 \%$, 回收总值为 5149.4 亿元, 同比下降 $20.1 \%$ 。

“十三五”以来，中国政府相继推行了两网融合、“互 联网+”回收模式等措施办法, 不断调整再生资源产业政策, 完善再生资源体系, 加大对再生资源产业的扶持力度。目 前, 中国再生资源产业仍处在初期发展阶段, 市场空间庞 大, 产业发展存在整体技术水平不高, 企业自主创新能力 不足, 相关人才培养难以与企业需求对接, 公众参与度不 高等问题。再生资源产业的外部性和产品的准公共物品属 性, 使得政府在引导该产业发展上具有较为重要的作用, 有效认识和评价再生资源产业发展现状, 分析影响再生资 源产业技术效率的因素，丰富中国政府对再生资源产业统 筹规划的技术手段, 是当前迫切需要解决的问题之一。

\section{2. 文献综述}

针对中国再生资源产业的发展现状, 许多学者提出了 问题和建议。周宏春（2010）对再生资源行业初具规模、 各区域发展形成特色、技术水平有所提升的现状进行阐述, 同时分析了中国再生资源产业存在的行业监管不到位, 市 场秩序混乱, 企业规模小, 技术水平低以及由此所造成的 二次污染, 配套法律法规与制度不完善等问题[1]。王培暄 (2011) 重点研究了中国再生资源产业发展中存在的立法 滞后、税收政策缺陷、市场准入规则缺失, 导致的无序竞 争等问题[2]。赵娟, 周火平 (2013) 分析了再生资源产业 的外部性、劳动密集和技术密集以及市场分散特征, 认为 中国再生资源产业存在综合利用率低, 政府管理部门的分 工存在部门分割、职能交叉、机构重叠问题, 以及政府政
策扶持和资金投入不足等问题[3]。张菲菲等 (2014) 研究 发现当前国内再生资源企业在规模扩张过程中对农民工 的雇佣力度远大于对大学生的招聘力度, 对业务员和拆解 工的需求也要远高于对技术研发人员的需求, 往往用直接 购置设备取代技术装备的研发, 由此导致了高校院所资源 循环专业人才培养与企业人才需求难以对接的问题, 加上 公众对再生资源产业的认识不足, 结果使得大量资源循环 专业的本科生转向其他专业[4]。2016年周宏春在会议中指 出中国再生资源利用没有摆脱引进国外淘汰技术的窠白, 加快自主技术进步进程势在必行 [5]。2017年的《废弃资源 再生循环利用产业专利信息分析及预警研究报告》指出在 中国废弃资源再生循环利用领域中, 申请人在专利运营方 面缺乏长期有效的策略, 在关键技术和开发深度上投入不 足，技术开发与产业需求结合不足[6]。

关于再生资源产业发展的区域性问题, 郭庭政 (2009) 通过定量辨识的方法, 发现2005年广东、湖南、浙江三省 再生资源产业集群初步形成, 并以区位摘为因变量构建回 归模型, 利用2005-2007年中国25个省份的相关指标统计 数据, 分析了再生资源产业集群可能的影响因素[7]。李健 和唐燕 (2012) 则采用综合区位熵指数, 选取2003-2009 年渤海地区五个省市的相关统计数据, 计算再生资源产业 的分指标区位摘及综合区位熵, 并按测算结果对各省市进 行时空差异分析, 结果显示天津市为该产业发展的核心区 域[8]。王瑞雪（2012）通过选取东三省2004年-2010年再 生资源产业的相关数据对再生资源产业进行区位摘计算, 从而分析三省再生资源产业化水平的差异[9]。

针对再生资源产业发展的影响因素方面, 有学者进行了 理论和实证分析。张菲菲, 李慧明 (2009) 从替代关系角度 分析了再生资源与初始资源价格波动的关联性对资源消费 市场结构和再生资源产业的影响 [10]。Bartomiej Kołsut （2016）分析城市间废弃物回收管理机构的空间分布规律、 制度条件以及财务动机三个因素对波兰城市间废弃物回收 管理规模的影响[11]。曾孟夏和赵彦云（2014）利用企业的 相关数据进行了实证分析, 结果表明与传统资源产业不同, 再生资源产业并非是在资源丰富的地区优先发展; 再生资源 产业与区域创新和服务业发展水平均呈显著的正相关关系, 相反采矿业与区域创新和服务业发展水平均不具显著的相 关关系[12]。高艳红等 (2015) 采用系统GMM估计方法, 利 用2005-2012年中国21个省市的面板数据, 考察再生资源产 业替代对经济增长质量的影响, 发现再生资源产业替代与经 济增长质量之间呈现显著的“倒U型”曲线关系[13]。

关于再生资源产业的技术效率的研究数量很少。 Simon等（2014）对2010年比利时35家废弃物回收利用企 业的技术和成本效率进行了实证研究 [14]。蒲勇健和种海 港等 (2014) 利用Malmquist指数方法, 利用2005-2012年 的面板数据, 测算了中国 21 个省市再生资源产业的全要素 生产率, 结论表明, 总体上中部地区全要素生产率的增长 速度最快, 东部次之, 西部最慢 [15]。蒲勇健和余显兰等 （2014）运用SFA方法分析了中国19个省市的再生资源产 业技术效率差异, 并考察了经济发展水平、城镇化水平、 
教育水平、工业发展水平和地理区域因素对再生资源产业 生产无效率和技术效率值的影响[16]。

综合上述文献可以看出, 中国再生资源产业的发展尚 不成熟，在人才、技术、政策、法规等方面存在诸多问题， 现有的评价再生资源产业技术效率的方法存在一定局限 性, 在影响因素的研究方面, 选取的指标还不够完善, 没 有考虑到如专利技术研发、再生资源进出口贸易、外商投 资等因素对再生资源产业技术效率的影响, 因此本文将运 用DEA方法对中国再生资源产业技术效率进行评价, 并着 力研究影响再生资源产业技术效率的分解值一纯技术效 率和规模效率的外部因素。

\section{3. 中国再生资源产业技术效率评价}

本文利用由美国著名学者Charnes、Cooper (1978) 提 出的DEA方法对再生资源产业技术效率进行测度, 选取 BCC 模型, 该模型将技术效率值分解为纯技术效率和规模 效率，能够分别从产业规模、技术水平和管理能力等不同 角度, 对产业的技术效率进行分析评价。

\section{1. 变量选取及数据来源}

本文选取了2010-2015年中国17个省市的再生资源产 业的相关数据, 其中规模以上废弃资源综合利用业从业人
数和规模以上废弃资源综合利用业主营业务成本作为投 入变量, 规模以上废弃资源综合利用业总产值作为产出变 量。在其他条件不变的情况下, 作为人力资本的从业人员 总数越小则效率越高。主营业务成本是指企业生产和销售 与主营业务相关的产品或服务所投入的直接成本, 主要包 括原材料、人工成本和固定资产折旧等。虽然不是企业运 营的全部费用成本额, 但可以用它代表废弃资源综合利用 业的成本。总产值是指物质生产部门的常住单位在一定时 期内生产的货物和服务的价值总和, 反映物质生产部门生 产经营活动的价值成果。大多数学者在选取产出变量时都 采取工业总产值、企业附加值或产业增加值。为了消除价 格因素的影响, 使用各省市的工业品出厂价格指数对各年 当年价格表示的工业总产值进行平减 (以2010年为基期)。 本文数据来源于2011-2016年《中国统计年鉴》以及各省 (市) 的地方统计年鉴。

\section{2. 实证结果与分析}

（1）全国再生资源产业三大效率演进

对2010-2015年间，17个省市的平均技术效率、平均 纯技术效率、平均规模效率演进情况进行分析, 根据图 1 可以发现, 中国再生资源产业的技术效率与纯技术效率变 化趋势一致, 而与规模效率的变化趋势呈现分化。

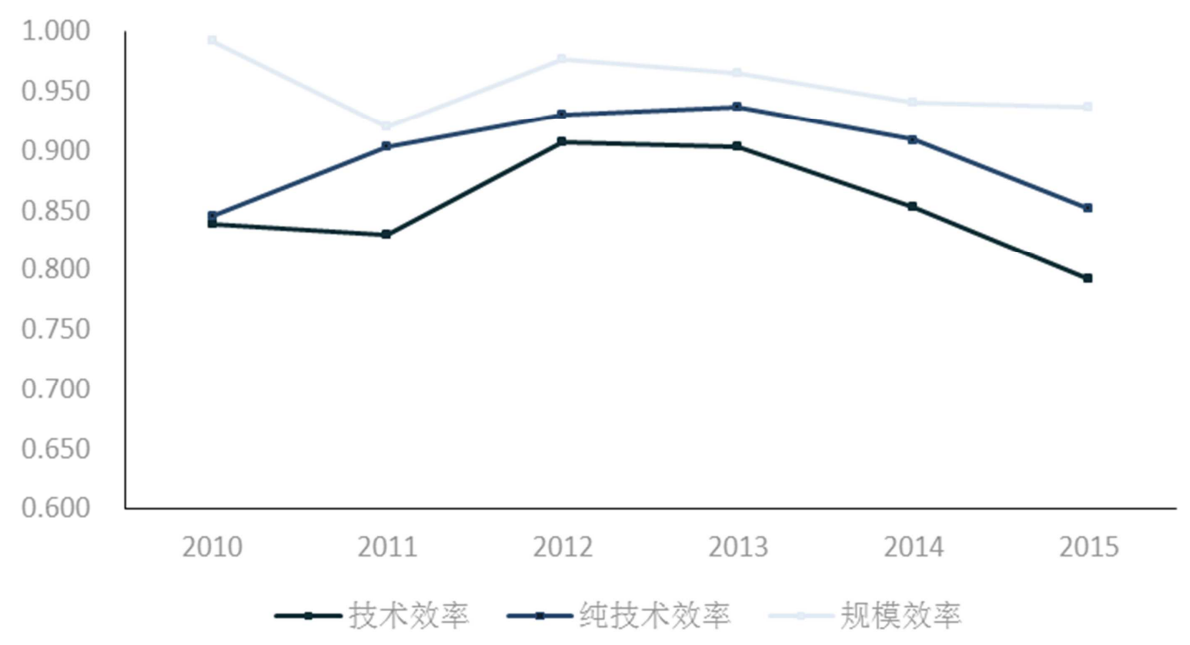

图12010-2015年中国再生资源产业技术效率及其分解值变化。

（2）各省市再生资源产业技术效率演进

技术效率是对决策单元 (DMU) 的资源配置能力、 资源使用效率等多方面能力的综合衡量与评价。

根据表1中的实证结果来看, 中国17个省市2010-2015 年再生资源产业的平均技术效率值均小于 1 , 没有达到 DEA有效。

分地区来看，2010-2015年中部和西部地区平均技术 效率值高于东部地区 ${ }^{1}$ 。考虑到本研究涉及的省市数量具 有局限性, 单纯按城市地理位置划分区域类别, 进行效率

1本文中的东部地区包括北京、天津、河北、上海、江苏、浙江、山东、 广东 8 个省份, 中部地区包括吉林、黑龙江、安徽、江西、湖北、湖南6 个省份, 西部地区包括重庆、四川、陕西3个省份。
值的比较, 无法清晰的反映所考察的所有省市再生资源产 业的技术效率水平。因此, 本文分省市, 分年份对再生资 源产业的技术效率进行了比较。

对各省市2010-2015年再生资源产业的平均综合技术 效率值进行排序, 结果显示, 中国华南、华东地区以及部 分中西部省市的平均技术效率排名较为靠前, 华北地区省 市的技术效率相对落后了一些。其中, 湖南省再生资源产 业平均综合技术效率排名第一。西南地区重庆和四川位列 第二、第三，安徽、江苏、广东排名也较为靠前。

针对各个年份, 对各省市技术效率进行分析, 可以看出, 湖南省和安徽省在2012-2014年间, 技术效率均为 1 , 达到了 DEA有效, 而2015年技术效率小于1, 为非DEA 有效。 
有学者的研究显示, 湖南省由于废弃资源回收利用行 业发展起步早, 基础深厚, 近年再生资源产业发展成效显 著, 产业模式已较为先进, 建成了汨罗国家循环经济工业 园、湖南永兴国家经济工业园、益阳沧水铺镇包装工业园, 再生资源交易市场较为活跃, 对于再生资源产业整体的效 率水平的提升起到积极的作用。
在2015年经济下行, 资源类商品价格大幅下跌的情况 下, 仅天津市技术效率为 1 , 相比其余省市均为非DEA有 效的结果, 表现突出。结合李健 (2012) 对环渤海地区再 生资源产业的时空差异分析成果, 天津市是再生资源产业 在环渤海地区发展的最核心区域, 作为全国循环经济试点 单位, 受到了政策扶持和地区经济发展带动作用, 产业技 术效率提升受到积极影响。

表1 2010-2015年各地区再生资源产业技术效率值。

\begin{tabular}{|c|c|c|c|c|c|c|c|c|}
\hline 年份 & 2010 & 2011 & 2012 & 2013 & 2014 & 2015 & 平均值 & 排名 \\
\hline 湖南 & 0.843 & 0.897 & 1.000 & 1.000 & 1.000 & 0.978 & 0.953 & 1 \\
\hline 重庆 & 1.000 & 1.000 & 0.924 & 0.908 & 0.886 & 0.844 & 0.927 & 2 \\
\hline 四川 & 0.910 & 0.818 & 0.960 & 1.000 & 1.000 & 0.782 & 0.912 & 3 \\
\hline 安徽 & 0.725 & 0.789 & 1.000 & 1.000 & 1.000 & 0.924 & 0.906 & 4 \\
\hline 广东 & 1.000 & 0.877 & 0.930 & 0.978 & 0.908 & 0.731 & 0.904 & 5 \\
\hline 江苏 & 0.797 & 0.875 & 1.000 & 0.942 & 0.820 & 0.719 & 0.859 & 6 \\
\hline 吉林 & 0.770 & 0.736 & 0.910 & 0.954 & 0.887 & 0.889 & 0.858 & 7 \\
\hline 北京 & 0.878 & 1.000 & 0.990 & 0.789 & 0.788 & 0.674 & 0.853 & 8 \\
\hline 湖北 & 0.987 & 0.753 & 0.770 & 0.910 & 0.861 & 0.793 & 0.846 & 9 \\
\hline 浙江 & 0.791 & 0.825 & 0.892 & 0.937 & 0.869 & 0.726 & 0.840 & 10 \\
\hline 山东 & 0.777 & 0.816 & 0.933 & 0.959 & 0.840 & 0.705 & 0.838 & 11 \\
\hline 河北 & 0.535 & 0.909 & 0.949 & 0.874 & 0.843 & 0.910 & 0.837 & 12 \\
\hline 黑龙江 & 0.992 & 0.701 & 0.873 & 0.798 & 0.685 & 0.878 & 0.821 & 13 \\
\hline 天津 & 0.745 & 0.616 & 0.822 & 0.812 & 0.895 & 1.000 & 0.815 & 14 \\
\hline 江西 & 0.858 & 0.910 & 0.748 & 0.931 & 0.783 & 0.630 & 0.810 & 15 \\
\hline 上海 & 0.705 & 0.786 & 0.816 & 0.813 & 0.891 & 0.769 & 0.797 & 16 \\
\hline 陕西 & 0.937 & 0.797 & 0.898 & 0.748 & 0.549 & 0.517 & 0.741 & 17 \\
\hline 东部 & 0.779 & 0.838 & 0.917 & 0.888 & 0.857 & 0.779 & 0.843 & \\
\hline 中部 & 0.863 & 0.798 & 0.884 & 0.932 & 0.869 & 0.849 & 0.866 & \\
\hline 西部 & 0.949 & 0.872 & 0.927 & 0.885 & 0.812 & 0.714 & 0.860 & \\
\hline 平均值 & 0.838 & 0.830 & 0.907 & 0.903 & 0.853 & 0.792 & 0.854 & \\
\hline
\end{tabular}

（3）各省市再生资源产业纯技术效率演进

纯技术效率指在决策单元 (DMU) 达到最优规模时 的投入要素的生产效率, 反映DMU的技术和管理水平。

根据表2中再生资源产业纯技术效率实证结果分析, 中国 17 个省市中, 只有广东省平均纯技术效率值为 1 , 达 到DEA有效。

对各省市2010-2015年再生资源产业的平均纯技术效 率值进行排序, 结果显示, 广东省再生资源产业平均综合 技术效率排名第一, 华北地区仅有北京市技术效率值排名 第三, 较为靠前, 河北、天津两省市纯技术效率值排名靠 后。华东地区安徽省排名第五, 而江苏、浙江位于中游, 上海远远落后, 排名倒数第一。华中地区湖南省排名第二,
远高于排名落后的湖北和江西。西南地区重庆、四川技术 效率值排名靠前。东北地区城市中黑龙江的纯技术效率值 排名仅次于北京, 远高于吉林省。西北地区陕西省的纯技 术效率值排名落后于大多数省市。

针对各个年份, 对各省市纯技术效率进行分析, 可以 看出, 广东省纯技术效率值在2010-2015年期间, 均达到 了DEA有效, 华北地区北京市、华中地区湖南省、华东地 区安徽省, 东北地区黑龙江省的纯技术效率达到DEA有效 的年份均在4年以上。西北地区陕西省在2010-2012年期间, 纯技术效率均为DEA有效, 西南地区重庆、四川以及华东 地区的江苏有2年达到了纯技术效率DEA有效。

表2 2010-2015年各地区再生资源产业纯技术效率值。

\begin{tabular}{|c|c|c|c|c|c|c|c|c|}
\hline 年份 & 2010 & 2011 & 2012 & 2013 & 2014 & 2015 & 平均值 & 排名 \\
\hline 广东 & 1.000 & 1.000 & 1.000 & 1.000 & 1.000 & 1.000 & 1.000 & 1 \\
\hline 湖南 & 0.844 & 1.000 & 1.000 & 1.000 & 1.000 & 0.979 & 0.971 & 2 \\
\hline 北京 & 0.882 & 1.000 & 1.000 & 0.895 & 1.000 & 1.000 & 0.963 & 3 \\
\hline 黑龙江 & 1.000 & 0.709 & 1.000 & 1.000 & 1.000 & 1.000 & 0.952 & 4 \\
\hline 安徽 & 0.746 & 0.934 & 1.000 & 1.000 & 1.000 & 1.000 & 0.947 & 5 \\
\hline 重庆 & 1.000 & 1.000 & 0.942 & 0.925 & 0.919 & 0.858 & 0.941 & 6 \\
\hline 四川 & 0.912 & 0.875 & 0.965 & 1.000 & 1.000 & 0.783 & 0.923 & 7 \\
\hline 江苏 & 0.797 & 1.000 & 1.000 & 0.946 & 0.863 & 0.756 & 0.894 & 8 \\
\hline 浙江 & 0.791 & 0.931 & 0.915 & 0.952 & 0.931 & 0.825 & 0.891 & 9 \\
\hline 吉林 & 0.772 & 0.780 & 0.923 & 0.994 & 0.917 & 0.907 & 0.882 & 10 \\
\hline 湖北 & 0.989 & 0.819 & 0.772 & 0.913 & 0.862 & 0.794 & 0.858 & 11 \\
\hline 山东 & 0.778 & 0.877 & 0.936 & 0.965 & 0.844 & 0.707 & 0.851 & 12 \\
\hline
\end{tabular}




\begin{tabular}{|c|c|c|c|c|c|c|c|c|}
\hline 年份 & 2010 & 2011 & 2012 & 2013 & 2014 & 2015 & 平均值 & 排名 \\
\hline 河北 & 0.535 & 0.951 & 0.952 & 0.878 & 0.846 & 0.914 & 0.846 & 13 \\
\hline 天津 & 0.754 & 0.696 & 0.822 & 0.813 & 0.941 & 1.000 & 0.838 & 14 \\
\hline 陕西 & 1.000 & 1.000 & 1.000 & 0.860 & 0.600 & 0.543 & 0.834 & 15 \\
\hline 江西 & 0.860 & 0.960 & 0.753 & 0.939 & 0.784 & 0.631 & 0.821 & 16 \\
\hline 上海 & 0.706 & 0.826 & 0.826 & 0.835 & 0.943 & 0.785 & 0.820 & 17 \\
\hline 东部 & 0.780 & 0.910 & 0.931 & 0.911 & 0.921 & 0.873 & 0.888 & \\
\hline 中部 & 0.869 & 0.867 & 0.908 & 0.974 & 0.927 & 0.885 & 0.905 & \\
\hline 西部 & 0.971 & 0.958 & 0.969 & 0.928 & 0.840 & 0.728 & 0.899 & \\
\hline 平均值 & 0.845 & 0.903 & 0.930 & 0.936 & 0.909 & 0.852 & 0.896 & \\
\hline
\end{tabular}

（4）各省市再生资源产业规模效率演进

规模效率反映的是实际规模与最优生产规模的差距。

根据表3中再生资源产业规模效率实证结果分析, 中 国17个省市的平均规模效率值均小于 1 , 非DEA有效。

对各省市2010-2015年再生资源产业的规模效率值进 行排序, 结果显示, 河北省再生资源产业平均规模效率排 名第一，华北地区天津排名中游，北京排名靠后，华东地 区上海市排名中游, 江苏、安徽、浙江排名靠后。华南地
区广东省排名位于中下游。华中地区江西省排名第二, 湖 北、湖南处于中游水平, 东北地区吉林排名中游, 黑龙江 排名倒数第一。西北地区陕西排名较为落后。

针对各个年份, 对各省市技术效率进行分析, 可以看 出, 湖南省和安徽省在2012-2014年间, 规模效率均为 1 , 达到了DEA有效。2015年, 仅天津市规模效率为 1 , 相比 其余省市均为非DEA有效的结果, 表现突出。

表3 2010-2015年各地区再生资源产业规模效率值。

\begin{tabular}{|c|c|c|c|c|c|c|c|c|}
\hline 年份 & 2010 & 2011 & 2012 & 2013 & 2014 & 2015 & 平均值 & 排名 \\
\hline 河北 & 1.000 & 0.956 & 0.996 & 0.995 & 0.996 & 0.996 & 0.990 & 1 \\
\hline 江西 & 0.998 & 0.948 & 0.994 & 0.992 & 0.999 & 0.999 & 0.988 & 2 \\
\hline 四川 & 0.998 & 0.935 & 0.995 & 1.000 & 1.000 & 0.999 & 0.988 & 3 \\
\hline 山东 & 0.999 & 0.931 & 0.996 & 0.994 & 0.995 & 0.997 & 0.985 & 4 \\
\hline 重庆 & 1.000 & 1.000 & 0.981 & 0.982 & 0.964 & 0.985 & 0.985 & 5 \\
\hline 湖北 & 0.998 & 0.919 & 0.998 & 0.996 & 0.999 & 0.998 & 0.985 & 6 \\
\hline 上海 & 0.999 & 0.952 & 0.987 & 0.974 & 0.945 & 0.980 & 0.973 & 8 \\
\hline 吉林 & 0.997 & 0.944 & 0.986 & 0.959 & 0.967 & 0.981 & 0.972 & 9 \\
\hline 天津 & 0.988 & 0.884 & 1.000 & 0.999 & 0.951 & 1.000 & 0.970 & 10 \\
\hline 江苏 & 1.000 & 0.875 & 1.000 & 0.996 & 0.950 & 0.951 & 0.962 & 11 \\
\hline 安徽 & 0.972 & 0.845 & 1.000 & 1.000 & 1.000 & 0.924 & 0.957 & 12 \\
\hline 浙江 & 1.000 & 0.886 & 0.975 & 0.985 & 0.933 & 0.879 & 0.943 & 13 \\
\hline 广东 & 1.000 & 0.877 & 0.930 & 0.978 & 0.908 & 0.731 & 0.904 & 14 \\
\hline 北京 & 0.995 & 1.000 & 0.990 & 0.882 & 0.788 & 0.674 & 0.888 & 16 \\
\hline 黑龙江 & 0.992 & 0.989 & 0.873 & 0.798 & 0.685 & 0.878 & 0.869 & 17 \\
\hline 东部 & 0.998 & 0.920 & 0.984 & 0.975 & 0.933 & 0.901 & 0.952 & \\
\hline 中部 & 0.993 & 0.924 & 0.975 & 0.958 & 0.942 & 0.963 & 0.959 & \\
\hline 西部 & 0.978 & 0.911 & 0.958 & 0.950 & 0.960 & 0.978 & 0.956 & \\
\hline 平均值 & 0.992 & 0.920 & 0.976 & 0.965 & 0.941 & 0.937 & 0.955 & \\
\hline
\end{tabular}

\section{4. 再生资源产业技术效率影响因素分析}

\section{1. 指标选取及数据来源}

由于再生资源产业技术效率可分解为纯技术效率和 规模效率的乘积, 本文将直接对纯技术效率和规模效率的 影响因素进行分析。结合前文对中国再生资源产业发展现 状和存在问题的分析, 本文认为, 循环经济产业园区的构 建加强了工业企业间的关联性，中国再生资源产业集群能 够在一定程度上提升行业整体技术效率, 然而对 17 个省市 技术效率的测算分析发现, 中国各省市再生资源产业的技 术效率存在明显的差异。由于产业运作是一个复杂的系统, 无法如企业所有者一样熟悉掌握企业内部运营的微观数 据, 很难对影响再生资源产业技术效率的因素进行全面的
考察分析, 考虑到数据的可得性问题, 本文侧重于研究分 析外部因素对中国各省市再生资源产业技术效率的影响。 参考相关的理论分析, 本文认为影响再生资源产业纯技术 效率和规模效率的主要外部因素是经济发展水平、产业结 构、对外开放程度、技术创新水平和教育水平。本文选择 反映影响因素的指标如下:

（1）用以 2010 年为基期的不变价人均GDP的对数值反映 区域经济发展水平, 记为lavrgdp。对于再生资源产 业的发展而言, 经济发展水平发展在一定程度上对 其起到基础支撑作用。但由于再生资源产业的外部 性, 行业平均利润水平较低, 经济发展水平较高的 地区由于资金流向选择较多, 人力成本较高, 也有 可能抑制再生资源产业的发展。 
（2）选取与再生资源产业密切相关的工业产出比重, 记 为sed。再生资源产业与工业尤其是制造业具备很强 的产业关联性，例如金属治炼及压延加工业、金属 制品业与再生资源产业具有很强的环向关联性，可 以认为制造业发展水平的高低在很大程度上决定了 再生资源产业发展水平的高低。本文假设工业产出 水平提升对纯技术效率和规模效率的两种可能影响 方向:

i：工业产出水平的提升来源于技术、设备和工艺的 改进, 则其对再生资源产业的纯技术效率和规模效率的 影响都将是正的;

ii：工业产出水平的提升来源于粗放型的生产经营方 式, 则其对再生资源产业的纯技术效率和规模效率的影 响可能是负的。

（3）选取第三产业产出占比反映产业结构。产业结构升 级常常表现为第三产业占比的提升, 而产业结构升 级所带来的产业关联、产业协同效率的提升，对于 再生资源产业纯技术效率和规模效率的提升可能存 在正向的影响。

（4）选用进出口贸易额与GDP的比值来衡量外贸规模, 记为tra。中国再生资源产业承接了国外废弃物的加 工处理环节, 一般而言, 对外贸易带来的专业化国 际分工能够提高纯技术效率。但不合理的对外贸易 结构可能会阻碍再生资源产业规模效率的提高。

（5）选用外商直接投资占GDP的比重反映外商直接投资, 记为fdi。许多学者通过实证研究发现fdi能够通过促 进行业竞争，间接促进东道国相关企业的工艺技术
和管理水平的提升, 例如卡特彼勒在上海投资发展 机械再制造业务, 对于上海市发展报废机电设备再 制造具有正向的影响，因此本文假设fdi的提升将推 动再生资源产业的纯技术效率的提升。

（6）选用专利授权数量与专利审计受理数量的比值反映 技术创新水平, 记为tech。较高的专利发明水平对于 再生资源产业的生产工艺水平可能存在正向影响。

(7) 选取具有大专以上学历的人口与六岁以上人口的比值 反映区域教育水平, 记为edu。区域教育水平在一定程 度上影响该区域从业人员受教育水平。在传统制造企 业中，从业人员受教育程度越高, 行业技术水平通常 较高。然而随着中国人口红利的消失, 劳动成本显著 提升, 教育水平高带来的直接结果通常是劳动成本的 上涨，对于处于初级发展阶段的中国再生资源产业而 言, 意味着高技术水平劳动力的流失和较大的成本压 力, 最终对再生资源产业纯技术效率和规模效率的影 响可能都是负的。

\subsection{Tobit回归模型构建}

本文依据选取的指标, 建立了研究再生资源产业效率 影响因素分析的 Tobit 回归模型如式（1）、（2），其中 $y_{1 i}$ *表示在第一阶段运用数据包络模型所测算出的第 $\mathrm{i}$ 个 地区再生资源产业的纯技术效率值, $y_{2 i}$ *表示在第一阶段 运用数据包络模型所测算出的第 $\mathrm{i}$ 个地区再生资源产业的 规模效率值。

$$
\begin{gathered}
y_{n i}=c+\beta_{1} \text { lavrgdp }+\beta_{2} \text { ind }+\beta_{3} \text { thi }+\beta_{4} \text { tra }+\beta_{5} F D I+\beta_{6} \text { res }+\beta_{7} \text { edu }+\varepsilon_{\mathrm{i}}, \quad(\mathrm{n}=1,2 ; \mathrm{i}=1,2, \quad \ldots . ., 17) \\
y_{n i}=\left\{\begin{array}{l}
y_{n i}^{*}, y_{n i}^{*}<1 \\
1, y_{n i}^{*} \geq 1
\end{array}\right.
\end{gathered}
$$

\section{3. 实证结果及分析}

运用Stata 14.0软件, 得到相关的回归分析结果如表4所示。

表4 再生资源产业纯技术效率和规模效率影响因素分析。

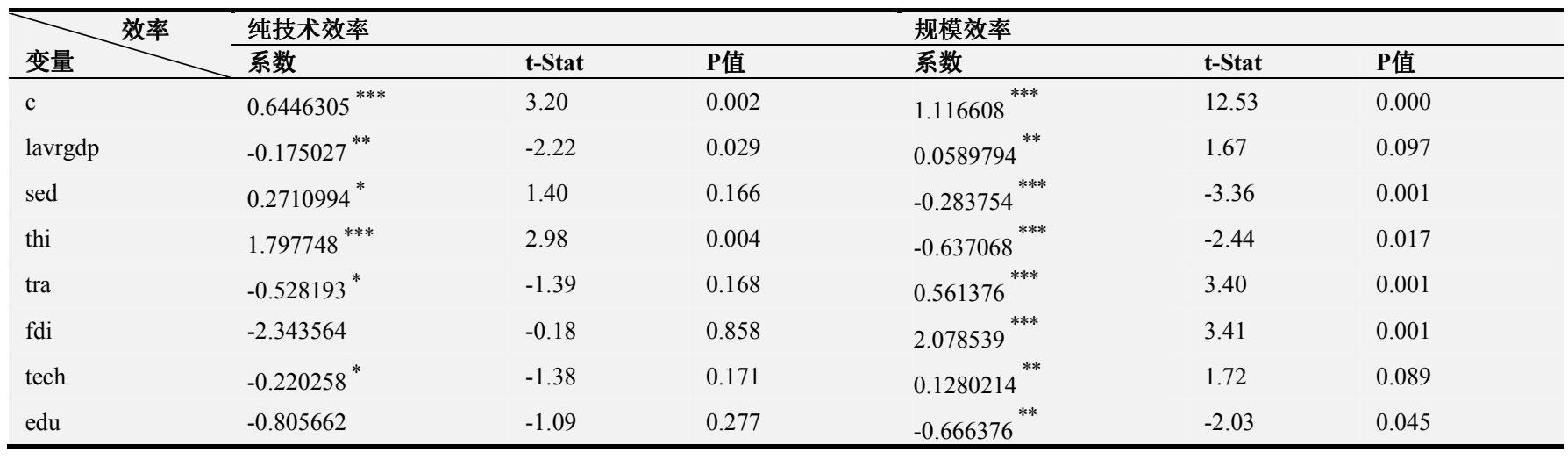

资料来源：根据各省市统计年鉴整理得到

注: $*$ 、**、***分别表示在 $10 \% 、 5 \% 、 1 \%$ 的水平下显著。 
人均GDP对再生资源产业纯技术效率与规模效率影 响的方向不一致。人均GDP在 $5 \%$ 的显著性水平下促进了 再生资源产业规模效率的提高, 而在 $5 \%$ 的显著性水平下 阻碍了再生资源产业纯技术效率的提高。这一结果表明, 经济发展水平的提高促进再生资源产业规模效率的提高, 这主要得益于经济发展水平较高的省市所具备的较高的 市场化程度对再生资源产业产生的集聚效应以及整体较 低的人力成本, 近年来, 随着经济发展水平的提高, 人口 红利的消失, 中国的人力成本, 尤其是东部沿海城市的人 力成本逐渐提升, 资本优先选择流入利润丰厚、稳定性强 的行业, 再生资源产业应注重改善废弃物的回收、加工与 利用方式, 促进企业生产技术、工艺设备与管理水平的提 升。

工业占比sed对再生资源产的纯技术效率和规模效率 的影响方向并不一致。对于纯技术效率, 工业总产出占 GDP比重的提升, 能带来纯技术效率的提升, 且在 $10 \%$ 水 平上是显著的。而对于规模效率, 工业总产出占GDP比重 的提升, 在 $1 \%$ 的显著水平上阻碍了规模效率的提升。

第三产业占比 thi对于再生资源产业纯技术效率和规 模效率的影响都比较显著, 但方向不一致。对纯技术效率 的具有正向影响, 但对规模效率的影响是负向的, 且都在 $1 \%$ 的水平上显著, 对于纯技术效率的影响远大于对规模 效率的影响。

对外贸易 $\operatorname{tra}$ 和外商直接投资占比fdi对于再生资源产 业的纯技术效率和规模效率的影响方向都不一致。两者对 于规模效率都具有正向影响, 对于纯技术效率的影响均为 负向。其中, 外商直接投资fdi对于两种效率的影响要远大 于对外贸易 $\operatorname{tra}$ 对两者的影响。

从综合对外贸易和外商直接投资占比对再生资源产 业纯技术效率和规模效率的影响来看, 中国再生资源产业 虽然对废弃物进口有依赖, 但这种依赖对于规模效率的提 升有比较显著的作用, 而外商直接投资的增长带来的先进 管理和工艺技术并未对再生资源产业产生溢出效应, 只是 提升了规模效率。

技术创新水平tech对再生资源产的纯技术效率和规模 效率的影响方向也不一致。对于技术创新水平与规模效率 存在正向的关系, 而与纯技术效率存在负向的关系, 分别 在 $5 \%$ 和 $10 \%$ 的水平上显著。结合本文对技术创新水平这一 指标的衡量, 是专利授权对专利申请数量的比重, 可以认 为现阶段中国技术创新对于再生资源产业要素生产效率 的提升有正向影响, 但对于产业内技术和管理水平的改善 并没有起到促进作用。

教育水平edu对再生资源产业纯技术效率和规模效率 的影响都为负向, 对规模效率的负向影响在 $5 \%$ 的水平上 显著, 而对纯技术效率的负向影响并不显著。结合张菲菲 等 (2014) 对高校资源循环专业人才的培养难以与企业人 才需求对接这一问题的研究, 以及本文对教育水平这一指 标的衡量, 是学历在大专以上人群在六岁以上人口中的占 比, 说明高等教育水平人数的提升并不能从整体上对再生 资源产业从业人员素质水平的提升产生积极的影响, 公众 对再生资源产业的认识不足以及高校相关专业人才培养
方式的落后, 可能反而对该产业高素质人才的引入产生负 面影响。

\section{5. 结论与政策建议}

本文通过DEA方法测度了2010-2015年中国17个省市 再生资源产业的技术效率水平, 并运用Tobit回归模型对再 生资源产业纯技术效率和规模效率的外部影响因素进行 了分析。结果表明, 在纯技术效率方面, 中东部地区省市 再生资源产业占有优势, 而在规模效率方面, 中西部地区 省市表现好于东部地区省市; 纯技术效率受到工业和第三 产业发展的正向影响, 且较为显著, 区域经济发展水平, 对外开放水平，技术创新水平以及教育水平没有对其产生 积极影响; 规模效率受区域经济发展水平、对外开放程度 和技术创新水平的正向影响, 而教育水平、工业发展水平 和第三产业发展水平对其影响是负向的, 且影响均较为显 著。结合前文提到的有关学者的研究, 并考虑指标变量与 数据选取等因素, 可以认为本文的实证结果大体上反映了 中国再生资源产业现阶段的发展现状。

根据本文的实证结果, 要促进中国再生资源产业的发 展，应加强再生资源产业跨国、跨地区、跨城市的交流与 合作；促进再生资源产业与相关工业产业的协同发展，如 通过合理构建产业园区, 建立信息公共服务平台, 促使再 生资源产业与传统制造业协同发展; 促进再生资源产业与 第三产业的协同发展，政府可以通过减免税收等手段，提 升物流和信息技术服务行业对再生资源产业发展的基础 支撑作用; 加强普及再生资源回收利用知识, 政府应通过 與论宣传, 加强再生资源回收利用知识的公众普及度, 在 学校教育方面, 除了继续推动各高校设立再生资源回收利 用相关技术专业和再生资源管理专业, 还应在中小学教育 课程体系中, 增加再生资源回收利用的课堂和课外实践课 程, 使中国青少年儿童从小树立对再生资源回收利用的意 识。

\section{参考文献}

[1] 周宏春.中国再生资源产业发展现状与存在问题[J].中国科 技投资,2010(04):22-24。

[2] 王培暄.论中国现阶段再生资源法规政策的缺位与对策 [J]. 科学经济社会,2011,29(02):25-28。

[3] 赵娟,周火平.中国再生资源产业发展的现状及对策研究 [J]. 中国人口.资源与环境,2013,23(S2):150-153。

[4] 张菲菲,曹雅,付嘉,赵完北.再生资源产业人才需求与院校专 业人才培养分析 [J].再生资源与循环经济,2014,7(06):24-27。

[5] 张化冰.再生资源产业健康发展是循环型社会之基础国务院发展研究中心专家周宏春纵论再生资源的几个重大 问题 [J].资源再生,2016(03):18-23。 
[6] 张松.专利技术推动再生资源产业再上新台阶一《废弃资 源再生循环利用产业专利信息分析及预警研究报告》书评 [J].资源再生,2017(10):62-63。

[7] 郭庭政.中国资源再生产业集群化及其影响因素研究[D].大 连理工大学, 2009。

[8] 李健,唐燕,张吉辉.中国再生资源产业集聚度变动趋势及影 响因素研究[J].中国人口·资源与环境, 2012, (22)05: 94-100.

[9] 王瑞雪.东北三省再生资源产业化水平差异研究[D].东北财 经大学,2012。

[10] 张菲菲,李慧明.再生资源产业回收模式比较 [J].再生资源与 循环经济,2010, 03: 27-29。

[11] Bartłomiej Kołsut. Inter-Municipal Cooperation in Waste Management: The Case of Poland[J]. Quaestiones Geographicae, 2016, 35(2).
[12] 曾孟夏,赵彦云.中国再生资源产业现状与趋势分析一一发 展、集聚兼与经济的协动 [J].现代管理科学,2014(12):64-66。

[13] 高艳红,陈德敏,张瑞.再生资源产业替代如何影响经济增长 质量?一中国省域经济视角的实证检验 [J]. 经济科 学,2015(01):18-28。

[14] Simon De Jaeger,Nicky Rogge. Cost-efficiency in packaging waste management: The case of Belgium[J]. Resources, Conservation \& Recycling, 2014, 85.

[15] 蒲勇健,种海港,张勇.中国再生资源产业全要素生产率估算 分析 [J].统计与信息论坛,2014,10:40-45。

[16] 蒲勇健,余显兰,张勇.中国再生资源产业的技术效率及影响 因素研究——基于随机前沿超越对数生产函数的分析 $[\mathrm{J}]$. 工业技术经济,2014,33(12):3-10。 